Qualitative research on the Belgian Cancer Rehabilitation Evaluation System (CARES): An evaluation of the content validity and feasibility Peer-reviewed author version

SCHOUTEN, Bojoura; HELLINGS, Johan; Vankrunkelsven, Patrick; MEBIS, Jeroen; BULENS, Paul; Buntinx, Frank; VANDIJCK, Dominique \& Van Hoof, Elke (2017) Qualitative research on the Belgian Cancer Rehabilitation Evaluation System (CARES): An evaluation of the content validity and feasibility. In: JOURNAL OF EVALUATION IN CLINICAL PRACTICE, 23(3), p. 599-607.

DOI: $10.1111 /$ jep.12681

Handle: http://hdl.handle.net/1942/24349 
3

4

5

\section{'Qualitative research on the Belgian Cancer Rehabilitation Evaluation System (CARES): An evaluation of the content validity and feasibility.'}

Schouten B., Hellings, J., Vankrunkelsven, P., Mebis J., Bulens, P., Buntinx, F., Vandijck D., Van Hoof E.

\section{Corresponding author:}

Bojoura Schouten, MSc, PhD-student, Faculty of Medicine and Life Sciences, Hasselt University, Martelarenlaan 42, 3500 Hasselt, Belgium \& Voluntary research assistant, Faculty of Psychological and Educational Sciences, Free University of Brussels, Pleinlaan 2, 1050, Elsene, Belgium, Contact information: Tel.: +32 112685 06, Fax: /, Mail: bojoura.schouten@uhasselt.be

Other authors:

Johan Hellings, PhD, Professor, Faculty of Medicine and Life Sciences, Hasselt University, Martelarenlaan 42, 3500 Hasselt, Belgium \& Managing director, AZ Delta Hospital, Rode-Kruisstraat 20, 8800 Roeselare, Belgium.

Patrick Vankrunkelsven, PhD, Professor, Department of Public health and Primary Care, Faculty of Medicine, KU Leuven, Kapucijnenvoer 33, PB 7001, 3000 Leuven, Belgium \& Director, Belgian Center for EvidenceBased Medicine (CEBAM), Kapucijnenvoer 33- blok J, 3000 Leuven, Belgium.

Jeroen Mebis, PhD, Professor, Faculty of Medicine and Life Sciences, Hasselt University, Martelarenlaan 42, 3500 Hasselt, Belgium \& Medical Oncologist, Jessa Hospital, Stadsomvaart 11, 3500 Hasselt, Belgium.

Paul Bulens, MD, Radiologist, Jessa Hospital, Stadsomvaart 11, 3500 Hasselt, Belgium.

Frank Buntinx, PhD, Professor, Department of Public health and Primary Care, Faculty of Medicine, KU Leuven, Kapucijnenvoer 33, PB 7001, 3000 Leuven, Belgium.

Dominique Vandijck, PhD, Professor, Faculty of Medicine and Life Sciences, Hasselt University, Martelarenlaan 42, 3500 Hasselt, Belgium \& Professor, Faculty of Medicine and Health Sciences, Ghent University, De Pintelaan 185, 9000 Ghent, Belgium \& Managing Director, ICURO, Brussel, Belgium.

Elke Van Hoof, PhD, Professor, Department of Experimental and Applied Psychology, Faculty of Psychological and Educational Sciences, Free University of Brussels, Pleinlaan 2, 1050 Elsene, Belgium.

Suggested running title: Evaluation content validity and feasibility CARES

KEYWORDS: cancer, quality of life, care needs, assessment, patient-centeredness 
41 ABSTRACT

RATIONALE, AIMS AND OBJECTIVES: The systematic assessment of cancer patients well-being and care needs is internationally recommended to optimize comprehensive cancer care. The Cancer Rehabilitation

44 Evaluation System (CARES) is a psychometrically robust quality of life and needs assessment tool of US origin, developed in the early '90s. This article describes Belgian patients' view on the content validity and feasibility of the CARES for use in current cancer care.

METHOD: Participants were cancer patients recruited through media. Data were gathered in four focus groups $(n=26)$. The focus group discussions were facilitated with key questions. A moderator and an observer conducted and followed the discussion. The audio file was transcribed verbatim and afterwards analyzed thematically.

RESULTS: Participants experience concerns and needs in a wide range of life domains: physical, emotional, cognitive, social, relational, sexual, financial, work-related and in the interaction with care professionals. According to participants, the items of the CARES are all relevant to capture the possible life disruption that cancer patients and survivors experience. One important theme is missing in the CARES, namely the well-being of loved ones. The completion time of the CARES was judged to be feasible, and according to participants only a few items need a reformulation .

CONCLUSION: In general, the results of this study support the content validity and feasibility of the CARES. However, little adjustments in formulation and a few extra items are needed. The instrument can be used to obtain a comprehensive assessment of cancer patients' overall well-being and care needs to take dedicated action in care. 


\section{INTRODUCTION}

Cancer is a disease with a huge impact, going far beyond the threat of physical health. Patients and survivors often struggle with multifactorial consequences of physical, psychological (cognitive, emotional), and social nature (1-3). Since scientific evolutions increased survival in the cancer patient population, attention for quality of life (QOL) in cancer care became more and more important. Along with other vital signs (temperature, blood pressure, pulse, respiratory rate and pain), distress or psychosocial well-being is considered the 'sixth vital sign' that deserves follow-up in cancer care (4-6).

Most patients do not disclose their psychological problems spontaneously, they rather frequently wait on the initiative of their doctor to discuss psychosocial topics (7). The majority of specialists working in medical oncology acknowledge the need to detect psychosocial distress. Though, clinicians are not always accurate in identifying patients who are significantly distressed and often underestimate emotional matters in patients (8). A mutual expectation of doctors and patients that the other will introduce the topic often leaves psychosocial concerns undiscussed (7). Care providers should ensure to minimize barriers for patients to disclose emotional issues (8). The use of a screening or assessment instrument prevents doctors from having to ask questions that they may feel are intrusive to the patient. Therefore, for example in Europe, Australia and the United States, guidelines were developed to systematically screen for levels of psychosocial distress and care needs of cancer patients (9-15). In Belgium there are no such guidelines, and psychosocial screening is not standardly applied in cancer care. A limitation in Belgian research and practice is the absence of a validated comprehensive assessment instrument to identify psychosocial concerns and care needs of cancer patients. However, multidomain screening can facilitate the dialogue between patients and clinicians and help detect distress $(16,17)$. A subsequent in-depth assessment of distressed individuals could determine which unmet needs have contributed to distress and give insights for triage and referral to different levels of intervention appropriate to each patient. In this way, a stepped care approach supported by the use of screening or assessment results would contribute to the organization of a more patient-centered and cost-efficient care.

In several systematic reviews (17-19), the psychometric qualities of needs assessment tools were compared, mainly resulting in a positive evaluation of the Cancer Rehabilitation Evaluation System (CARES), and the Supportive Care Needs Survey (SCNS). Since the researchers believe that the CARES assesses 'health' care needs with the greatest depth in terms of biopsychosocial content, this instrument was chosen for further use. The CARES is a QOL and needs assessment instrument, developed in the nineties to provide an efficient way of gathering specific information about the day-to-day problems and rehabilitation needs of cancer patients. In the 
past this instrument was successfully used for research and clinical purposes (20-24). Unfortunately, the widespread use of the CARES was limited by a copyright and user fee imposed by the developers. Since the user fee was abolished in November 2012 the instrument gained further visibility in research (25-28).

The time perspective, culture and language are important for the ecological dimension and validity of an instrument. A correct adaptation for a different language and culture requires a broader design that takes into account linguistic as well as technical and conceptual aspects in measuring health status (29). Since the CARES was not frequently used in recent years, the validity in current patient populations is still uncertain. To resolve this issue, new validation research had to be undertaken. Two studies were conducted to examine the validity of the CARES for the Belgian population: a quantitative study on the translation and validation of the Belgian CARES was conducted to examine the psychometric robustness of the instrument in terms of reliability, construct validity and concurrent validity $(30,31)$, and the qualitative study that is described in this article. The aim of this qualitative study is to involve the target population, namely Belgian cancer patients, in answering the following questions: 'Is the content of the CARES relevant and complete enough to have the potential to capture the QOL and supportive care needs of Belgian patients?' and 'Is the CARES an acceptable and feasible instrument for these patients?'

\section{METHODS AND MATERIALS}

The method of focus group (FG) discussions was used to deepen our understanding of participants' experiences and the meaning they attribute to such experiences. The diversity of participants in the group ensured that the insights on the discussion topic were obtained from different angles and perspectives, and not merely based on individual opinions. This is important for this study since it needed to explore the degree to which the content of the CARES allowed to capture the QOL and supportive care needs of Belgian patients in general. Each participant was encouraged to actively participate in the discussion.

\section{Participants and setting}

Participants were adult cancer patients recruited through a call in the local newspaper and on the radio in May 2014. There were no restrictions on type and time of cancer diagnosis, gender and age ('adult' was defined as 18 years and older). Patients were excluded when they lacked proficiency in Dutch as this would hamper their participation in the focus group discussions. The FGs took place in the course of the summer of 2014 in 'Huis 

The resulting 'thematic map' was used to code all FG data. support to cancer patients, survivors and their relatives.

\section{The QOL and needs assessment tool} in Table 1.

\section{Procedure} (Table 2). Each FG lasted about 120 minutes.

\section{Data analysis}

Erika Thijs', an open and well accessible house in Hasselt, Belgium, which offers various non-professional

The original CARES contains 139 items (min. 93 and max. 132 applicable per person). Patients can rate each item, formulated as problem statement, on a 5-point ordinal scale with zero representing "not at all" (no problem) and four representing "very much" (severe problem). Additionally, patients are asked to indicate for which problems they would want help, ticking 'yes' or 'no' to the question 'Do you want help?'. The items of the CARES can be placed under 31 subscales, and subsequently taken together in six summary scales as shown

Interested patients were contacted and the date of their participation was registered. One week before FGs took place, participants were sent an envelope containing an information letter, an informed consent form, and a short questionnaire on socio-demographics, type of cancer and treatment. They were asked to fill in these documents and bring them to the FG. All participants provided informed consent before taking part in this validation study, which was approved by the local medical ethics committee. A copy of the CARES was also included in the preparatory documentation for the participants, so that they could get acquainted with the assessment tool and bring it to the FG.-The moderator (BS) and an observer (WE or EVH) conducted and followed the FG discussion while it was audiotaped with prior consent. The group discussion was facilitated with several key questions

The digital audio files of the focus groups were transcribed verbatim (BS) and analyzed using thematic content analysis (32-34). FGs were organized until data saturation was reached. Through repeated reading of transcriptions, initial codes were noted by two independent readers (BS and EVH). Subsequently the codes were organized into meaningful groups and combined in overarching themes. After reviewing the subdivision of themes, categories and codes were given to two naïve readers (JH and PV) to revise for semantic correctness. 


\section{RESULTS}

\section{$151 \quad$ Participants}

152 Twenty-six cancer patients participated in four FG discussions (with seven, six, six and seven participants,

153 respectively). The mean age was 56.2 years (range 28-78). Counts and percentages of further socio-demographic 154 and medical characteristics are displayed in Table 3.

155

\section{Qualitative analysis results}

The FGs resulted in a large data corpus. All themes are shown in Supplementary file 1. However, only the data set relevant to content validity and feasibility of the CARES will be described in this article.

Three themes divided in subthemes are discussed below. The first, 'Cancer and treatment related consequences', contains the subthemes 'complaints and symptoms', 'financial impact', 'work-related impact' and 'well-being loved ones'. The second theme is 'Interaction with care professionals'. The third theme, 'Assessment of psychosocial well-being and care needs', is divided in the subthemes 'experiences with patient-reported outcome measures in care', 'content CARES' and 'feasibility CARES'. For each theme a few example quotes are presented in Table 4. More quotes can be found in Supplementary file 2.

\section{THEME: CANCER AND TREATMENT RELATED CONSEQUENCES}

\section{COMPLAINTS AND SYMPTOMS}

Cancer patients mentioned experiencing different kinds of physical consequences of cancer treatment. A common complaint is the lack of energy making it difficult for people to regain their former level of activity. Some patients experience limitations due to pain in the muscles or joints, loss of taste, or deterioration of the skeleton. Temporary or permanent loss of fertility is a frequent concern for female patients since it can change their future family perspectives.

Participants experience psychological consequences in terms of changes in cognitive functioning, emotions and personality. Memory problems are often named, as well as feelings of fear, sorrow, loneliness, anger, shame, guilt, insecurity, etc. Before they recognized these emotions patients were often overwhelmed and not aware of their perception of the situation. For some, the experience was so heavy and hopeless that thoughts about the desire to be dead came to their mind. 
Social life changes occurred, either because the patient was pushing others away or because their context became avoidant. Likewise, the opposite was experienced if the context of the patient responded supportively and involved itself: relationships became closer and new friendships arose.

Patients marital and sexual life is put to the test. The patient and their partner sometimes cope with the situation differently leading to relational tension. Damaged as well as strengthened relationships are experienced. Likewise, physical and emotional aspects can induce a discrepancy in sexual needs. Amputations, scarves, baldness and weight gain affect people's body image and sometimes influences their sense of masculinity or femininity.

\section{FINANCIAL IMPACT}

The confrontation with cancer was also said to increase the health expenditure and induce huge financial burden on those not properly insured. Even with good insurance, the loss of income requires adequate spending and sometimes a change of life style. Even years after being cured from cancer, one can experience problems with financial benefits like the application for a mortgage, insurances, scholarships, reimbursements, etc.

\section{WORK-RELATED IMPACT}

Patients working as independent entrepreneurs mentioned that they often have difficulties to stop working during treatment because of the risk to lose clients and income, and they therefore cannot stay at home to focus on treatment and recovery. For patients on sick leave, a part of their social context is missing because there is no more daily contact with colleagues. Once returned to work there is sometimes little understanding for the altered ability to work and the risk to be fired arises.

\section{WELL-BEING LOVED ONES}

Most participants talked about the impact their disease experience had on their loved ones. Partners, children and parents had to change their lives to take care of the patient, manage the household on their own, deal with the fact that their loved one was sick and possibly incurable. Some participants notice feelings of fear, anger or sorrow in their partners or children, others don't know how their loved ones are coping with the situation because the topic is avoided. According to participants, there is a lack of attention for the well-being of patients' loved ones in cancer care.

\section{THEME: INTERACTION WITH CARE PROFESSIONALS}

Patients expect a comprehensive approach including medical care and psychosocial support. They report positive and negative experiences with care mostly determined by aspects such as trust, personal approach, 
multidisciplinary cooperation and referral, follow-up, holistic approach, availability/time, communication style, clarity of information and familiarity with patients' medical or personal situation.

\section{THEME: ASSESSMENT OF PSYCHOSOCIAL WELL-BEING AND CARE NEEDS}

\section{EXPERIENCES WITH PATIENT-REPORTED OUTCOME MEASURES IN CARE}

Some participants had to complete questionnaires on their physical functioning for the insurance company or other institutions. Their experiences with these questionnaires were negative. According to participants the questions were too limited to properly assess aspects that matter for insurance companies. Only three participants were familiar with the use of a patient-reported outcome tool in clinical care to assess and follow-up their psychosocial well-being and care needs. They received the Distress Thermometer and Problem List in follow-up. Their experiences on the use of this tool were positive.

\section{POTENTIAL ROLE OF PSYCHOSOCIAL SCREENING}

According to our participants, the use of a psychosocial screening tool could be of great value in practice. An instrument with questions on the overall well-being could give help recognize patients' experiences and normalize the taboo of psychosocial problems. Using psychosocial screening tools could also lower the threshold to mention concerns and needs and stimulate the communication between patients and caregivers. In this way, problems and care needs could be detected more easily by caregivers and allow them to provide input for designated action in care.

\section{APPLICABILITY OF PSYCHOSOCIAL SCREENING}

The potential value and applicability of psychosocial screening depends on personal situation, personality, preferences, and approachability.

According to cancer patients a screening instrument should be readily accessible and concise. When certain concerns or problems are denoted, a more profound assessment can follow.

Repeated application of screening and assessment is seen as desirable by participants since well-being and supportive care needs can change. The desired timing for psychosocial screening differs according to personal experiences with the disease, treatment and recovery.

If screening and assessment were applied in practice, the majority of our FG participants would prefer to complete this in a paper version. Some reasons often mentioned include better concentration, limited burden on the eyes, ability to fill in anywhere, and lack of familiarity with the computer. Environmental concerns, the speed 
of filling in a screening and processing of results nonetheless made other participants prefer screening in a digital format.

Participants emphasize that the use of psychosocial screening can only be valuable if the obtained insights yield to action and if revealed needs are monitored in follow-up and matched to the appropriate care.

CARES

243 The whole content of the CARES is seen as relevant and important for the wellbeing of someone confronted with cancer, though this can vary according to the phase of the disease-trajectory one is going thorough or according to one's personal situation. Topics mentioned as most important are mostly physical and daily functioning, emotional well-being and relations with loved ones. Generally, the content of the CARES is judged to be complete. According to several participants, one very important element is missing in the CARES as well as in cancer care, namely the well-being of their relatives. Likewise, feelings of uncertainty and loneliness associated with cancer are experienced by several participants and insufficiently discussed in the CARES. Feasibility CARES

The CARES is experienced as a long questionnaire, yet participants find this acceptable considering the importance of capturing people's overall wellbeing rigorously for utility in cancer care. The formulation of the CARES in general is positively evaluated, and everything was clear for the participants. The only comment that was raised is that the questionnaire might be difficult for non-native Dutch speakers because of the vocabulary used. Some suggestions were raised to reformulate a few items to clarify or to make the formulation less confronting. The 'yes'/'no' response categories linked to the question 'Do you want help?' were also seen as an issue as sometimes neither 'yes' nor 'no' would fully allow patients to express themselves. One participant suggested that some people might get anxious when they are confronted with some of the items, such as 'my clothes do not fit anymore', 'relapse', and 'the emotional experience'.

After the qualitative analysis process, all data was reviewed again and CARES items were ticked if the topic was discussed. Most items of the CARES (103/139) were covered spontaneously by participants in the FG discussion (Supplementary file 3). A great percentage of the non-discussed items are the items that do not apply to all patients (e.g. 'Difficulties to help the children cope'). 
The findings of this study, along with the quantitative research on the psychometric robustness of the instrument (31), show a positive evaluation of the validity of the CARES.

As in other research populations participants in this study experience concerns and needs in a wide range of life domains $(1-3,35)$. Physical problems, limitations in daily functioning as well as memory problems are often named. The confrontation with cancer, related treatment and consequences may cause feelings of fear, sorrow, loneliness, anger, shame, guilt and insecurity. Social life changes took place for some, and both marital and sexual life are challenged. Work related and financial consequences are experienced not only in the active phase of disease and treatment, but also later on.

The interaction with professional care givers plays an important role in the extent to which concerns are addressed and care needs are met. Similar to other studies our data suggest that patients frequently want their doctor to initiate discussion of psychosocial topics (7), or at least to minimize barriers to disclose emotional issues (8). For participants, an important concern - and sometimes even a real burden - was the well-being of loved ones. Patients partners and children sometimes struggled with the situation, but this was not noticed nor discussed in the care system. The use of screening and assessment tools could initiate and facilitate the dialogue between patients and clinicians regarding psychosocial topics and promote early identification of patients' distress and related needs $(16,17)$.

The findings of our qualitative data collection are congruent with past study results on the content of the original CARES $(36,37)$, namely that the content of the instrument is very relevant. In the literature on the original CARES, no substantive shortcomings were mentioned. In our sample however, the absence of items on the experience of loneliness and well-being of loved ones were explicitly stated as lacking. Participants noticed a considerable impact of their disease and treatment regime on the lives and the well-being of their spouses, parents and children. Patients often perceived the concern for their loved ones as burdensome, but this difficulty was not recognized nor detected by health care professionals and might also be undetected by the CARES since the questionnaire contained no item on this topic. In our future studies, we will explore the addition of the missing topics in the Belgian CARES screening tool. Our participants judged the CARES to be a feasible instrument. Completion of the instrument is experienced to be time consuming, but acceptable. In our quantitative study which was conducted to test the psychometric qualities of the CARES (31), data showed that all CARES item were indicated as being a problem for $0.6-88.1 \%$ of the participants, and therefore relevant for a population of cancer patients. Nonetheless, the suggestion was made to previously conduct a shorter screening version and to subsequently assess patients' QOL and needs 
more profoundly with the CARES if distress is detected. These preferences are in favor of a stepped-screening approach. The CARES-Short Form, which includes 59 items of the full version, could potentially be used for such initial screening purpose $(38,39)$. The original CARES items were constructed with involvement of patients $(36,40)$. However, according to participants of this study, some items of the CARES could be adjusted with simpler or less confronting vocabulary to optimize feasibility. Most participants favor completing a paper version. Nevertheless, according to them both a paper and digital version should be available for the application of the instrument in clinical practice. This would tailor psychosocial screening to individual convenience. Several methodological considerations about this study should be mentioned. First, the representativeness of the research population can be discussed. With a mean age of 56.2 years (range 28-78), our research population was slightly younger than the average Belgian population of cancer patients, where respectively 66 percent of the women and 77 percent of the men are 60 years or older at the time of diagnosis. The recruitment of participants via media potentially gave opportunity for the emergence of a self-selection bias. Nevertheless, results on the socio-demographic and medical characteristics show that the study sample is comparable to the general populations of cancer patients in Belgium (41). Compared to the proportion found in the general Belgian population of cancer patients, more women than men participated in our study. However, this is often seen in psycho-oncology research, presumably because men are less prone to talk about psychosocial concerns $(42,43)$. Participants were recruited without specification of cancer type, which led to a strong representation of breast cancer patients in the research population. However, this is in accordance with the prevalence of this type of cancer in our female population. In all likelihood, findings can be applicable for the broader population of cancer patients in Belgium. Secondly, no participants with a low proficiency in Dutch and few people with a low level of education participated in the FGs, yet these people represent a significant proportion of the Belgian society. Thirdly, the neutrality of the study setting can be questioned. 'Huis Erika Thijs' was chosen for the FGs to take place given that it is outside the hospital context, centrally located, and that the care offer of the initiative could be discovered by participants visiting the center. Some FG participants had never heard of 'Huis Erika Thijs', some had heard of it before, but the majority of the group did not visit the center before. If the location was of influence for some participants, the effect probably was not uniform. Fourthly, in this study only the full version of the CARES was discussed with participants, although, the CARES-Short Form was also validated in Flemish. Letting patients compare both versions in content, completeness and feasibility would have been interesting. We suggest that future research efforts should aim to enhance understanding of the feasibility of the CARES for immigrants and patients with a low level of education. More future research could aim to compare between the 
content and feasibility of the short and long CARES version, as well as on the key points for implementation of effective QOL screening and needs assessment in clinical practice.

In conclusion, the results of this study suggest the CARES is a feasible QOL and needs assessment instrument with acceptable content validity for use in a population of Belgian patients in current cancer care. The CARES can be used to detect a wide range of problems and care needs and according to patients, its use can be of value for the integration of psychosocial follow-up in supportive cancer care. In response to participants' input in this qualitative study, minor adjustments to the CARES will be made before it is further used in research and clinical practice: a few items regarding the well-being of loved ones will be added and the wording of some items will be adjusted. This will increase the ecological fit and validity of the instrument with the Belgian patient population in which we wish to use the CARES for further research and clinical application.

\section{ACKNOWLEDGEMENTS}

340 Our gratitude goes out to the team of Huis Erika Thijs for their hospitality and for the provision of facilities

341 during the focus groups. We would like to thank Willem van de Esschert for his practical support in conducting

342 the focus groups, Noémie Aubert Bonn for editing the manuscript for the English language, and Limburg Sterk

343 Merk (LSM) for funding the PhD-research project of Bojoura Schouten . 


\section{REFERENCES}

348 1. Sanson-Fisher R, Girgis A, Boyes A, Bonevski B, Burton L, Cook P. The unmet supportive care 349 needs of patients with cancer. Supportive Care Review Group.Cancer. 2000 Jan 1;88(1):226-37. 350 PubMed PMID: 10618627. Epub 2000/01/05. eng.

3512 2. Mikkelsen T, Sondergaard J, Sokolowski I, Jensen A, Olesen F. Cancer survivors' rehabilitation 352 needs in a primary health care context.Family practice. 2009 Jun;26(3):221-30. PubMed PMID: 35319264838.

3543 3. Harrison JD, Young JM, Price MA, Butow PN, Solomon MJ. What are the unmet supportive 355 care needs of people with cancer? A systematic review.Supportive Care in Cancer. 2009

356 Aug;17(8):1117-28. PubMed PMID: 19319577.

357 4. Holland JC, Bultz BD. The NCCN guideline for distress management: a case for making distress 358 the sixth vital sign.Journal of the National Comprehensive Cancer Network : JNCCN. 2007 Jan;5(1):3359 7. PubMed PMID: 17323529. Epub 2007/02/28. eng.

360 5. Bultz BD, Carlson LE. Emotional distress: the sixth vital sign--future directions in cancer 361 care.Psycho-oncology. 2006 Feb;15(2):93-5. PubMed PMID: 16444764. Epub 2006/01/31. eng. 6. Bultz BD, Johansen C. Screening for distress, the 6th vital sign: where are we, and where are we going?Psycho-oncology. 2011 Jun;20(6):569-71. PubMed PMID: 21626609. Epub 2011/06/01. eng.

7. Detmar SB, Aaronson NK, Wever LDV, Muller M, Schornagel JH. How are you feeling? Who wants to know? Patients' and oncologists' preferences for discussing health-related quality-of-life issues.J Clin Oncol. 2000 Sep 15;18(18):3295-301. PubMed PMID: WOS:000089433700013. English. 8. Mitchell AJ, Vahabzadeh A, Magruder K. Screening for distress and depression in cancer settings: 10 lessons from 40 years of primary-care research.Psycho-Oncology. 2011 Jun;20(6):572-84. PubMed PMID: WOS:000291113500002. English.

9. Medicine lo. Cancer Care for the Whole Patient: Meeting Psychosocial Health Needs. Washington, DC: The National Academies Press; 2008.

10. Accreditation C. Omentum program 2009 standards: cancer care and oncology services (ver 2). Ottawa, ON. 2008.

11. Network NCC. Distress management (v.1.2008): National Comprehensive Care Network, Inc.; 2007 [cited 20156 March]. Available from: https://www.nccn.org/professionals/physician_gls/f_guidelines.asp.

12. Centre NBC. Clinical practice guidelines for the psychosocial care of adults with cancer. Camperdown2003.

13. Holland J, Watson M, Dunn J. The IPOS new International Standard of Quality Cancer Care: integrating the psychosocial domain into routine care.Psycho-oncology. 2011 Jul;20(7):677-80. PubMed PMID: 21710503. Epub 2011/06/29. eng.

14. UK National Institute of Clinical Excellence. Improving supportive and palliative care for adults with cancer. 2004 1-84257-579-1.

15. Government A. Australian clinical practice guidelines for the psychosocial care of adults with cancer, 2003. 2003.

16. Mitchell AJ. Screening for cancer-related distress: when is implementation successful and when is it unsuccessful?Acta oncologica (Stockholm, Sweden). 2013 Feb;52(2):216-24. PubMed PMID: 23320770. Epub 2013/01/17. eng.

17. Carlson LE, Waller A, Mitchell AJ. Screening for Distress and Unmet Needs in Patients With Cancer: Review and Recommendations.J Clin Oncol. 2012 Apr 10;30(11):1160-77. PubMed PMID: WOS:000302995700003. English.

18. Wen KY, Gustafson DH. Needs assessment for cancer patients and their families. Health and quality of life outcomes. 2004 Feb 26;2:11. PubMed PMID: 14987334. Pubmed Central PMCID: PMC394345. Epub 2004/02/28. eng. 
19. Richardson A, Medina J, Brown V, Sitzia J. Patients' needs assessment in cancer care: a review of assessment tools.Support Care Cancer. 2007 Oct;15(10):1125-44. PubMed PMID: WOS:000249632900002. English.

20. Ganz PA, Coscarelli A, Fred C, Kahn B, Polinsky ML, Petersen L. Breast cancer survivors: psychosocial concerns and quality of life.Breast cancer research and treatment. 1996;38(2):183-99. PubMed PMID: 8861837. Epub 1996/01/01. eng.

21. Ganz PA, Desmond KA, Leedham B, Rowland JH, Meyerowitz BE, Belin TR. Quality of life in long-term, disease-free survivors of breast cancer: a follow-up study.Journal of the National Cancer Institute. 2002 Jan 2;94(1):39-49. PubMed PMID: 11773281. Epub 2002/01/05. eng.

22. Ganz PA, Schag CA, Lee JJ, Sim MS. The CARES: a generic measure of health-related quality of life for patients with cancer.Quality of life research : an international journal of quality of life aspects of treatment, care and rehabilitation. 1992 Feb;1(1):19-29. PubMed PMID: 1301111. Epub 1992/02/01. eng.

23. Schag CA, Heinrich RL. Development of a comprehensive quality of life measurement tool: CARES.Oncology (Williston Park, NY). 1990 May;4(5):135-8; discussion 47. PubMed PMID: 2143399. Epub 1990/05/01. eng.

24. Schag CA, Ganz PA, Wing DS, Sim MS, Lee JJ. Quality of life in adult survivors of lung, colon and prostate cancer.Quality of life research : an international journal of quality of life aspects of treatment, care and rehabilitation. 1994 Apr;3(2):127-41. PubMed PMID: 8044158. Epub 1994/04/01. eng.

25. Khan F, Amatya B. Factors associated with long-term functional outcomes, psychological sequelae and quality of life in persons after primary brain tumour.Journal of neuro-oncology. 2013 Feb;111(3):355-66. PubMed PMID: 23292152. Epub 2013/01/08. eng.

26. Parker PA, Alba F, Fellman B, Urbauer DL, Li Y, Karam JA, et al. Illness uncertainty and quality of life of patients with small renal tumors undergoing watchful waiting: a 2-year prospective study.European urology. 2013 Jun;63(6):1122-7. PubMed PMID: 23419322. Pubmed Central PMCID: PMC3866912. Epub 2013/02/20. eng.

27. Zimmermann C, Swami N, Krzyzanowska M, Hannon B, Leighl N, Oza A, et al. Early palliative care for patients with advanced cancer: a cluster-randomised controlled trial.Lancet (London, England). 2014 May 17;383(9930):1721-30. PubMed PMID: 24559581. Epub 2014/02/25. eng. 28. Borstelmann NA, Rosenberg SM, Ruddy KJ, Tamimi RM, Gelber S, Schapira L, et al. Partner support and anxiety in young women with breast cancer.Psycho-oncology. 2015 Mar 13. PubMed PMID: 25765893. Epub 2015/03/15. Eng.

29. Gjersing L, Caplehorn JR, Clausen T. Cross-cultural adaptation of research instruments: language, setting, time and statistical considerations. 2010;10(1):1-10.

30. Schouten B, Van Hoof E, Vankrunkelsven P, Schrooten W, Bulens P, Buntinx F, et al. Assessing cancer patients' quality of life and supportive care needs: Translation-revalidation of the CARES in Flemish and exhaustive evaluation of concurrent validity.BMC health services research. 2016;16(1):86. PubMed PMID: 26969509. Pubmed Central PMCID: PMC4788884. Epub 2016/03/13. eng.

31. Schouten B, Hellings J, Van Hoof E, Vankrunkelsven P, Bulens P, Buntinx F, et al. Validation of the flemish CARES, a quality of life and needs assessment tool for cancer care.BMC cancer. 2016;16:696. PubMed PMID: 27576341. Pubmed Central PMCID: PMC5006609. Epub 2016/09/01. eng.

32. Graneheim UH, Lundman B. Qualitative content analysis in nursing research: concepts, procedures and measures to achieve trustworthiness.Nurse education today. 2004 Feb;24(2):105-12. PubMed PMID: 14769454. Epub 2004/02/11. eng.

33. Braun V, Clarke V. Using thematic analysis in psychology. 2006 2006/01/01;3(2):77-101. 34. Kvale S. InterViews: An Introduction to Qualitative Research Interviewing. Thousand Oaks, CA: Sage; 1996. 
35. Ganz PA, Schag CC, Heinrich RL. The psychosocial impact of cancer on the elderly: a comparison with younger patients.Journal of the American Geriatrics Society. 1985 Jun;33(6):429-35. PubMed PMID: 3998352. Epub 1985/06/01. eng.

36. Schag CC, Heinrich, R.L., \& Ganz, P.A. . The Cancer Inventory of Problem Situations: An instrument for assessing cancer patients' rehabilitation needs. 1983;1(11-24).

37. Heinrich RL, Schag CC, Ganz PA. Living with cancer: the Cancer Inventory of Problem Situations.Journal of clinical psychology. 1984 Jul;40(4):972-80. PubMed PMID: 6480863. Epub 1984/07/01. eng.

38. Schag CA, Ganz PA, Heinrich RL. CAncer Rehabilitation Evaluation System--short form (CARESSF). A cancer specific rehabilitation and quality of life instrument.Cancer. 1991 Sep 15;68(6):1406-13. PubMed PMID: 1873793. Epub 1991/09/15. eng.

39. te Velde A, Sprangers MA, Aaronson NK. Feasibility, psychometric performance, and stability across modes of administration of the CARES-SF.Annals of oncology : official journal of the European Society for Medical Oncology / ESMO. 1996 Apr;7(4):381-90. PubMed PMID: 8805930. Epub 1996/04/01. eng.

40. Schag CA, Heinrich RL, Aadland RL, Ganz PA. Assessing problems of cancer patients: psychometric properties of the cancer inventory of problem situations. Health psychology : official journal of the Division of Health Psychology, American Psychological Association. 1990;9(1):83-102. PubMed PMID: 2323331. Epub 1990/01/01. eng.

41. BelgianCancerRegistry. Cancer Prevalence in Belgium 2010 Brussels: Belgian Cancer Registry, 2014.

42. Corney RH. Sex differences in general practice attendance and help seeking for minor illness.Journal of psychosomatic research. 1990;34(5):525-34. PubMed PMID: 2231486. Epub 1990/01/01. Eng.

43. Galdas PM, Cheater F, Marshall P. Men and health help-seeking behaviour: literature review.Journal of advanced nursing. 2005 Mar;49(6):616-23. PubMed PMID: 15737222. Epub 2005/03/02. Eng. 
TABLES

476 Table 1 Life domains covered by CARES summary scales and subscales

CARES Summary scales (n CARES Subscales
items)

\begin{tabular}{|c|c|}
\hline Physical (26) & $\begin{array}{l}\text { Ambulation } \\
\text { Activities of daily living } \\
\text { Recreational activities } \\
\text { Weight loss } \\
\text { Difficulty working } \\
\text { Pain } \\
\text { Clothing }\end{array}$ \\
\hline Medical Interaction (11) & $\begin{array}{l}\text { Problems obtaining info from medical team } \\
\text { Difficulty communicating with medical team } \\
\text { Control of medical team }\end{array}$ \\
\hline Marital $^{\mathrm{a}}$ (18) & $\begin{array}{l}\text { Communication with partner } \\
\text { Affection with partner } \\
\text { Interaction with partner } \\
\text { Overprotection by partner } \\
\text { Neglect of care by partner }\end{array}$ \\
\hline Psychosocial (44) & $\begin{array}{l}\text { Body image } \\
\text { Psychological distress } \\
\text { Cognitive problems } \\
\text { Difficulty communicating with friends/relatives } \\
\text { Friends/relatives difficulty interacting } \\
\text { Anxiety in medical situations } \\
\text { Worry } \\
\text { Interaction with children } \\
\text { At work concerns }^{\mathrm{a}}\end{array}$ \\
\hline Sexual (8) & $\begin{array}{l}\text { Sex interest } \\
\text { Sexual dysfunction }\end{array}$ \\
\hline Miscellaneous (32) & $\begin{array}{l}\text { Compliance } \\
\text { Economic barriers } \\
\text { Dating }^{\mathrm{a}} \\
\text { Chemotherapy-related problems }^{\mathrm{a}} \\
\text { Radiation-related problems }^{\mathrm{a}} \\
\text { Ostomy }^{\mathrm{a}} \\
\text { Prosthesis }^{\mathrm{a}} \\
\text { Miscellaneous items }^{\mathrm{a}}\end{array}$ \\
\hline
\end{tabular}

\footnotetext{
${ }^{\text {a }}$ Items do not apply to all patients.
} 
Table 2 Interview guide for the focus group

\begin{tabular}{ll}
\hline $\begin{array}{l}\text { Opening } \\
\text { question }\end{array}$ & 1. Can you please introduce yourself shortly and share with the group what your motivation was to \\
participate in this study? \\
Introductory \\
questions \\
professional asked you this and with what purpose? \\
Transition and key \\
The CARES is an assessment tool developed to explore the well-being and care needs of people \\
confronted with cancer. There are several aspects of well-being discussed, that we have listed for you. \\
3. If one wants to explore the well-being of cancer patients, which topics are according to you the most \\
relevant/important? Are they included in the CARES? Which topics are less important? \\
4. Are there topics not mentioned in the CARES that are important when one wants to explore cancer \\
patients' well-being? Which? \\
5. How did you experience the wording of the CARES-items? \\
6. If such an assessment tool or questionnaire would be integrated as a standard part in care, what \\
would be the value of this? \\
7. If you look back at the cancer care you have experienced until now, did a caregiver notice the \\
concerns and care needs you experienced? $*$ \\
8. How did they detect these? / How could they have detected these? * \\
9. What is the best way to introduce support in response to detected needs? *
\end{tabular}

Ending question Our goal was to get a clear perspective on the topics cancer patients consider important to be followed up in care and the properties an instrument should meet in order to serve this goal. Specifically, we have asked you to evaluate the content and acceptability of the CARES as an assessment tool. (+ summary of what is been said during the focus group discussion)

10. Is there something I have overlooked or something that still has to be discussed? 
Table 3 Participants' socio-demographic and medical characteristics

\begin{tabular}{|c|c|c|}
\hline \multirow[t]{2}{*}{ Participant Characteristics } & \multicolumn{2}{|c|}{$\mathrm{N}=\mathbf{2 6}$} \\
\hline & $\mathbf{n}$ & $\%$ \\
\hline \multicolumn{3}{|l|}{ Gender } \\
\hline Men & 4 & 15.4 \\
\hline Women & 22 & 84.6 \\
\hline \multicolumn{3}{|l|}{ Relational status a } \\
\hline Single & 2 & 7.7 \\
\hline In a relationship: living with partner/married & 22 & 80.8 \\
\hline In a relationship: not living with partner/married & - & - \\
\hline Widowed & 1 & 3.8 \\
\hline \multicolumn{3}{|l|}{ Children ${ }^{\text {a }}$} \\
\hline No & 3 & 11.5 \\
\hline Yes & 22 & 80.8 \\
\hline \multicolumn{3}{|l|}{ Level of education ${ }^{\text {a }}$} \\
\hline Elementary school & 1 & 3.8 \\
\hline High school & 9 & 24.6 \\
\hline Graduate school & 13 & 50.0 \\
\hline University & 1 & 3.8 \\
\hline \multicolumn{3}{|l|}{ Employment $^{\text {a }}$} \\
\hline Employed & 7 & 26.9 \\
\hline Work interruption/on sick leave & 2 & 7.7 \\
\hline Unemployed & 1 & 3.8 \\
\hline Disabled & 6 & 23.1 \\
\hline Housewife/houseman & - & - \\
\hline Retired & 8 & 30.8 \\
\hline \multicolumn{3}{|l|}{ Monthly household income ${ }^{\text {a }}$} \\
\hline$<€ 1500$ & 4 & 15.4 \\
\hline$€ 1500-€ 3000$ & 15 & 57.7 \\
\hline$>€ 3000$ & 4 & 15.4 \\
\hline \multicolumn{3}{|l|}{ Cancer diagnosis ${ }^{b}$} \\
\hline Breast & 11 & 42.3 \\
\hline Colorectal & 4 & 15.4 \\
\hline Lung & 1 & 3.8 \\
\hline Ovarian & 1 & 3.8 \\
\hline Non-Hodgkin Lymphoma & 2 & 7.7 \\
\hline Hodgkin Lymphoma & 2 & 7.7 \\
\hline Brain & 1 & 3.8 \\
\hline Prostate & 1 & 3.8 \\
\hline Thyroid & 1 & 3.8 \\
\hline Malignant melanoma & 1 & 3.8 \\
\hline Pancreas & 1 & 3.08 \\
\hline Liver & 1 & 3.8 \\
\hline Uterine body & 1 & 3.8 \\
\hline Other diagnosis & 1 & 3.8 \\
\hline \multicolumn{3}{|l|}{ Treatment $^{c}$} \\
\hline Surgery & 17 & 65.4 \\
\hline Chemotherapy & 15 & 57.7 \\
\hline Radiotherapy & 12 & 46.2 \\
\hline Hormonal therapy & 7 & 26.9 \\
\hline Immune therapy & 1 & 3.8 \\
\hline Bone marrow transplantation & 1 & 3.8 \\
\hline Other treatment & - & - \\
\hline
\end{tabular}

${ }^{\text {a }}$ Not all characteristics count up to $100 \%$ due to missing answers of some participants, ${ }^{\mathrm{b}}$ Cancer diagnosis in total counts up to more than $100 \%$, because several participants got diagnosed with more than one type of cancer in the course of time, ${ }^{\mathrm{c}}$ Treatment types in total counts up to more than $100 \%$, because most participants got treated with a combination of treatments. 
Table 4 Themes from thematic data analysis and example quotes

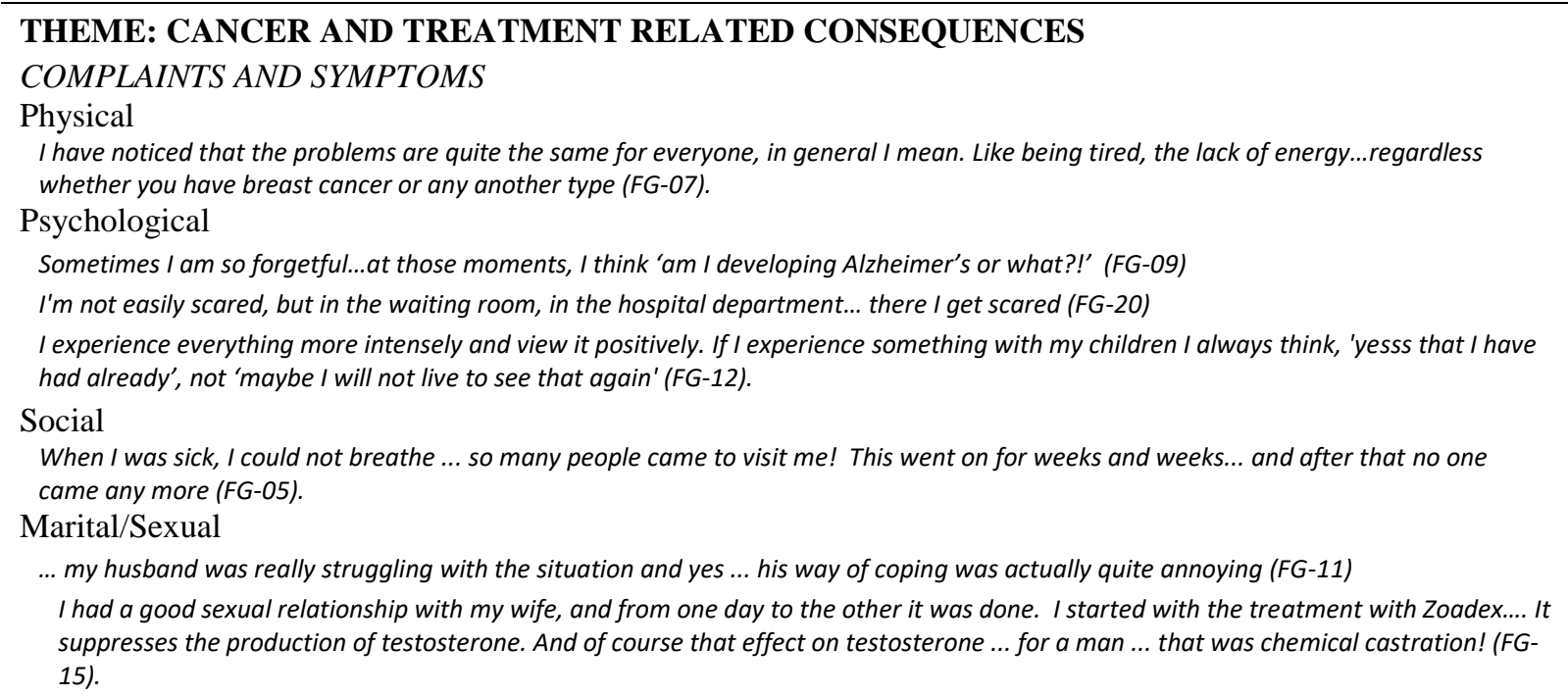

\section{FINANCIAL IMPACT}

We had bought our house on the basis of two full-time incomes, of which one failed because of my illness. But my loan will not decrease. It remains the same, the banks want their money (FG-06).

WORK RELATED IMPACT

I've heard ... as soon as my sick leave ends, I'm getting fired (FG-09).

I am independent, I cannot stop working, so I've just been working... but in in a limited way (FG-02).

WELLBEING LOVED ONES

My mom stayed at home to care for me. Their whole life changes and you already feel guilty and bad and then you also see them suffering from the situation ( $F G-10)$.

We get a lot of attention like 'how are you?', but the fear of the partner ... who possibly ends up alone... there is almost no one thinking about how they are doing (FG-14).

\section{THEME: Interaction with care professionals}

If they would have had attention for my deepest fear at the time I was sick to death of my chemo...the fear that said 'What if something goes wrong with me, what with my two sons?'...I think I would have been a lot more resilient to cope with the chemo (FG-26).

... the nursing staff were guardian angels for me. I had a lot of questions. They answered me and if there was something they didn't know, then the doctor came up with an answer. So I felt 'there is something happening here' (FG-13).

I have the experience that few doctors or specialists can identify with the psyche ... I think they are good technical people for surgery, but there are few who can empathize with the psyche of the patient (FG-17).

\section{THEME: Assessment of psychosocial well-being and care needs}

\section{EXPERIENCES WITH PATIENT-REPORTED OUTCOME MEASURES IN CARE}

Not from the hospital, but from the health insurance... a questionnaire on self-reliance...really ridiculous questions they ask you, like 'do you have a handrail on the toilet? They use these to score...to decide if you are disabled or not (FG-13).

The hospital sent me a questionnaire like that (like the CARES)... I experienced it as something positive that they are interested in your well-being. That there is follow-up of your situation even if you're not in the hospital anymore... I did me well (FG-25).

\section{POTENTIAL ROLE OF PSYCHOSOCIAL SCREENING}

Then you know 'what I feel is completely normal'...sometimes you feel abnormal, but if you know that there are other people that are feeling that way... and it is a topic in follow-up...you would feel a lot better already (FG-11).

Aaaaah yes, I admit I answered some questions I would never talk about with my oncologist... or even with my general practitioner. And yet I'd like to get help for those things, but I don't dare to bring it up myself (FG-06).

\section{APPLICABILITY OF PSYCHOSOCIAL SCREENING}

When I started with chemo I wasn't sick and I thought "well I'm doing good, everything is going perfect"... but after that first week I felt completely different (FG-06).

\section{CARES}

\section{Content CARES}

Everything is important, it depends on your own situation what is most. I can imagine that other aspects for some people are less important. I wouldn't let any topic out of the questionnaire (FG-21).

I think it certainly is important that there is attention for all those who are around you, how are they doing at that stage ... My partner, my children and so ... they also suffered a lot (FG-01).

Feasibility CARES

I think...if it would be possible to shorten it...everything must be addressed, but not too extensive (FG-12). 